\title{
Denuncia de Don Francisco de Val, un llamado a la vigilancia a la frontera imperial de Bacalar-Wallis, 1797
}

\section{Don Francisco de Val's denouncement, a call to vigilance in the imperial border of Bacalar-Wallis, 1797}

José Luis Ureña ArgaeZ*

doi. dorg/10.29043/liminar.v20i1.899

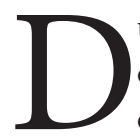
urante los años de 1796 a 1802, España e Inglaterra entraron en un conflicto armado enmarcado en las llamadas Guerras revolucionarias. Tuvo su origen el 14 de julio de 1789, año en que con la toma de la Bastilla inició la Revolución francesa, movimiento que ocasionó el fin de la monarquía de Francia y detonó un gran cambio político-social en el Viejo Mundo.

Este suceso provocó que las demás monarquías europeas emprendieran acciones hostiles para detener las fuerzas revolucionarias. Entre estas acciones se incluye una breve alianza que sostuvieron España e Inglaterra. Sin embargo, a pesar de la presión ejercida por ambas naciones, las fuerzas revolucionarias lograron arrinconar a España al invadir y ocupar las provincias vascongadas y Cataluña, lo que obligó a la Corona española a capitular y firmar el Tratado de Basilea en 1795, y al año siguiente ratificar el Tratado de San Ildefonso (Ferrero, 2004, p. 28), en el cual tanto España como Francia se comprometían a darse mutuo apoyo en caso de ser atacadas. Dicho convenio se realizó con la finalidad de debilitar y contrarrestar a Inglaterra, la cual poco a poco había construido un imperio colonial y así ganó la hegemonía mundial de los mares.

Mientras Europa y el Gran Caribe fueron escenarios de los grandes enfrentamientos que marcaron la línea que seguiría el conflicto hispano-inglés, en la frontera imperial de Bacalar-Wallis, tan solo un año antes de la derrota española en el Cayo de San Jorge (el 12 de septiembre de 1797), un oficial de la Corona, Francisco de Val, se dirigía al capitán general de Yucatán, Arturo O’Neill, para presentarle una queja sobre el comportamiento del gobernador español del presidio de San Felipe de Bacalar, el coronel Felipe María Codallos (Vázquez, 2016, p. 186).

A continuación se presenta la transcripción de dicho documento, encontrado en el Archivo General del Estado de Yucatán dentro del Apartado Colonial, Ramo Militar, vol. 1, exp. 8, año 1797, que lleva por título "Juan Francisco de Val denuncia al Capitán General O’Neill, las maliciosas maniobras del Gobernador de Bacalar en la expedición de la Costa de Chac". 


\section{Foja 1}

12 de Sept. 97

Aún la operaciones más fáciles, se hacen imposibles quando el que domina, no las apoya de buena fe, el espíritu del que manda en un lugar, principalmente, siendo miserable como este, tiene gran influencia en los corazones de estos subditos, quienes generalmente por conveniencias propias desean congratular al que los puede perjudicar ó favorecer, esto sin precision, y aquello sin motivo, ambos estímulos muy poderosos para hacer inútiles los formidables efectos de la maquinaria, que solo tiene virtud para multiplicar la potencia que la de impulso, mas no para producir esta, y menos para superar tantos estorbos como emplea este señor Governador contra la salida de las lanchas; en el modo de proporcionar los auxilio, al parecer proximo y su calidad, manifestándose este modo ser antipoda de mis aciertos, travajos, y buenos deseos de seguir al Rey.

Para convencimiento de esta verdad, acompañó a V.S. copia valida el N. $1^{\circ}$ del oficio que le envié en 9 de septiembre, y de su contestacion valida el N. $2^{\circ}$ en que Vera V.S. se desentiende.

\section{Foja 2}

enteramente de la peticion que le ago de los señores carpinteros Antonio Josef Gonzalez, y Pedro Buen, y los despide valiendose para concertar sus intencion de que me quedare yo sin el auxilio de Antonio Josef Gonzalez, que me pudiese mañana acolocar un sable, guindaleza vuestra del metodo de la suerte, oi que hizo entrar a todos los carpinteros, para decidir la suerte de los dos que debian quedarse toco estas a Joaquin Pavia, hombre de conducta tan relajada, que solo mi vondad, ha podido sacar algun fruto de el en la construcción de las lanchas, a fuerza de asaralos, como podran a V.S. declaran todos los carpinteros sin distinción: La segunda suerte recayó en Pablo Medrano, que casi siempre lo tuve enfermo de afecto del pecho. En este conflicto pude conseguir, que sacrificando Pablo Medrano 17 pesos y medio en favor 
de Antonio Josef Gonzalez para que se pusiese en su lugar: Mas adelante le pasé el oficio $\mathrm{N}^{\circ} 3$. por contestacion, conociera V.S. que Antipoda tan declarado esta de mis aciertos, por el modo de proporcionarme los auxilio, pues dice, que las providencias de los quince soldados de la tierra que me facilitan para cuenta a V.S. para que los convence de esta expedicionaria fatiga: como si toda la Provincia no supiera, que las maniobras de echar al agua las piraguas, bajarlas a Chac, jamás se ha empleado otra gente, que los soldados de la fion pues fuera de estos, y alguno que otro miliciano.

\section{Foja 3}

Urbano es gente absolutamente inútil, no solo para estas maniobras, sino para cualquiera otro trabajo, que sea muy suave.

En menos de nueve horas Señor Capitan General he ido a ver con asombro de todo este Pueblo los admirables efectos de la maquinaria, pues es dicho tiempo, y con solo 35 hombres que tuve hasta ayer a las cinco de la tarde, he padecido el vado que hay desde aquí a la laguna del Mariscal, el mar dilatado y el peor seguimiento doy los del país, de cuantos se encuentran de aquí a Cha, no solo por su poco fondo, sino por su calidad de un fango pegajosisimo; pero ya me ba faltando el espíritu, a fuerza de trabajar con una gente, que a la vista del mal exemplo de su gefe, el impedir ocultamente la salida de las lanchas, no quieren moverse, si no a palos.

Hoy mismo haviendome lastimado en un dedo de la mano, al zarpar la Anela, un soldado de la finca, que fue preciso vajando en tierra, se vajaron con el pretesto de enfermos dos negros de los que estan travajando en las lagunas, viendo yo esta picardía se los embié a decir al Governador para que me los bolbiere a remitir abordo, y su contestación fue, que del mismo modo, que se havía lastimado el soldado, podían ellos estar enfermos y que todos los demás creían que se lastimarian hasta no quedarme ningún hombre en Bacalar. De todo este pueblo, y de toda clase de gentes. 


\section{Foja 4}

han ido a bordo a ver marchar la diariamente y no hay uno, que no hay buelto admirado de la dulzura de las maniobras, y facilidad de un movimiento a poquísima fuerza que se emplee.

En una palabra Señor Governador: acompañado de todas estas fatigas, y falto hoy del unico marinero bueno que tenía pues por haberme caído enfermo para el manejo de los aparejos, pues todos los demás no entienden palabra, voy a continuar mi viaje a Chac, adonde espero llegar con toda felicidad, si no me falta el único sable y guindaleza que tengo, pero para la otra lancha, a que se le añadirán las pipas, que en lo mas principal, y que me ha faltado para esta. Si V.S. quiere que llegue a Chac inmediatamente, no tiene V.S, sino darle la comisión al mismo Governador, verá V.S. que (ilegible por quemadura) las cosas, que lo que han sido conmigo. yo aunque quiera, me parece, que podre viajar mas con la otra, pues considero quedare inútil de esta vez, hasta para poder hablar con las gentes. Dios cuide de V.S y Mercedes. Bacalar 12 de Septiembre de 1797. Juan de Val.

Imagen 1. Ficha del documento

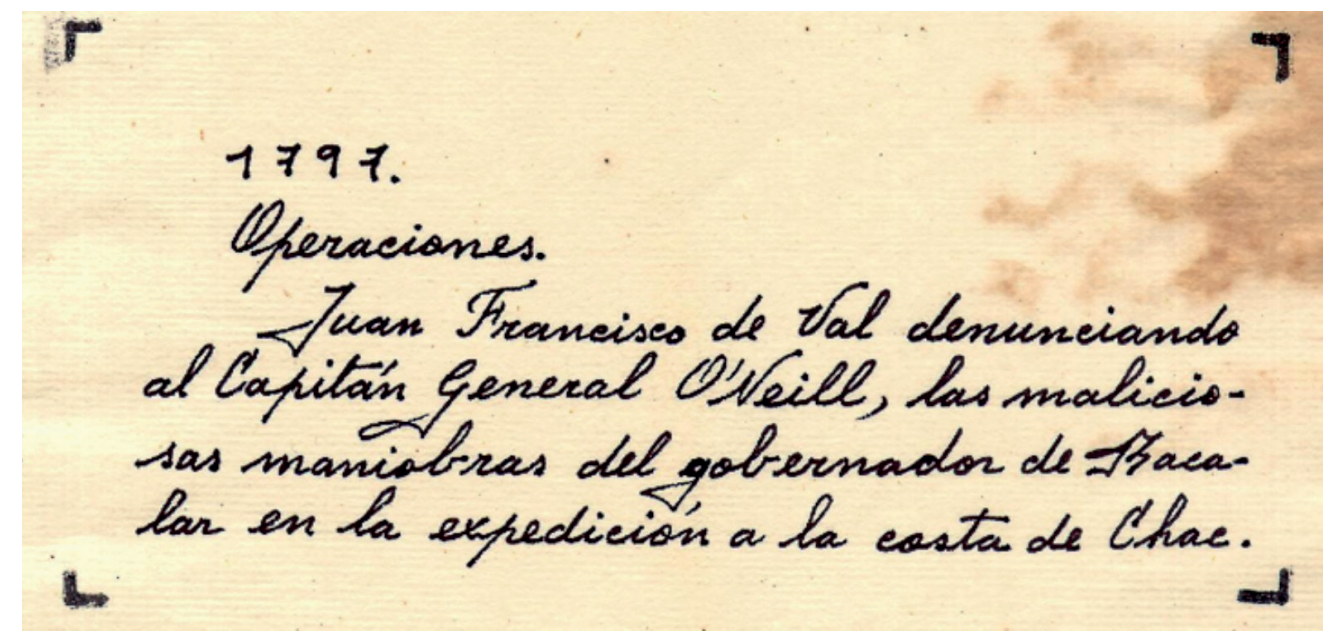

Fuente: Archivo General del Estado de Yucatán dentro del Apartado Colonial, Ramo Militar, vol. 1, exp. 8, año 1797. 
Como se ha mencionado, el documento fue redactado y firmado un año antes de la batalla del cabo de San Jorge, donde se enfrentaron las fuerzas españolas del capitán O’Neill con las británicas al mando del capitán John Moss, líder de los pobladores ingleses, y del superintendente de Wallis, Thomas Barrow. El enfrentamiento fue el último intento español por desalojar a los ingleses de la región, lo que no tuvo efecto debido a la victoria británica, la cual constituyó bases para legitimar la ocupación de Belice bajo derecho de conquista (Toussaint, 1996).

Este hecho expone una circunstancia importante: que las autoridades españolas tuvieron la iniciativa y la convicción de mantener bajo su control los territorios en torno a la Bahía de Chetumal, pero también demostraban, como el oficial Francisco de Val menciona, que, sobre las políticas bélicas imperiales, en el área funcionaban acuerdos no escritos que garantizaban la sobrevivencia en una frontera donde la colaboración con el "enemigo" era algo natural para mantenerse en una región marginada económicamente como fue la conformada por Wallis, la Laguna de Chac y las orillas de esta.

Este planteamiento se construye a partir de lo que apunta Francisco de Val cuando hace patente su enojo y decepción al expresar que desde el primer día el gobernador del presidio de Bacalar, Felipe María Codallos, comenzó a interponerse en las acciones del oficial real.

Este último, al llegar a Bacalar, hizo contacto con un carpintero, Antonio Josef González, para construir o reparar varias lanchas; sin embargo, el gobernador del presidio le hizo ver que, para hacer uso de los servicios de un carpintero del poblado, primero tenía que dirigir una solicitud al gremio, y estos le designarían a alguien para que le ayudara. Aparentemente, esto no tendría que haber supuesto un problema, pero el oficial De Val menciona que los carpinteros y el gobernador conjuraron y eligieron a dos artesanos incapaces de ayudarle, ya que uno era perezoso y el otro quejumbroso. Ante ello, el oficial real explicó que tuvo que disponer de su propio dinero, la suma de 17 pesos, para pagar el servicio del carpintero Antonio Josef González para el trabajo de las lanchas.

Solucionado el tema de las lanchas, al oficial De Val le tocó solicitar apoyo militar para su expedición, por lo que se dirigió al gobernador a fin de que este le facilitara gente. Codallos puso entonces a las órdenes del oficial a quince soldados indios y dos negros como guías. Sin embargo, los soldados indios no demostraron gran valor ya que constantemente se quejaban de la fatiga y el cansancio que les causaba la expedición, lo que retrasó el objetivo de la misión, mientras que los negros fingían lesiones para dejar de seguir sirviendo al oficial real.

En la parte final del texto, Francisco de Val menciona que, para colmo, el único marinero que hacía bien su trabajo cayó enfermo, por lo que quedó él solo ante la difícil situación. Cierra el documento con la súplica al capitán general O’Neill para que instruya al gobernador de Bacalar a fin de que acate las órdenes y le apoye.

Este testimonio muestra una pequeña pero interesante parte de la realidad que se vivió en la frontera imperial entre España e Inglaterra, donde las autoridades españolas aplicaban medidas de vigilancia, a pesar de que las poblaciones locales avecindadas en Bacalar poco cooperaban para obstruir su vinculación con el "enemigo" británico en apoyo de los funcionarios reales designados a la región bacalarense para darle buena vigilancia y protección. 


\section{Referencias}

Ferrero, J. A. (2004). Situación estratégica política anterior al combate de cabo de San Vicente. (Cuadernos monográficos del IHCN 47). Instituto de Historia y Cultura Naval. https:/armada.defensa.gob.es/archivo/ mardigitalrevistas/cuadernosihcn/47cuaderno/cap0l.pdf

Toussaint, M. (1996). Belice: una historia olvidada. Centro de Estudios Mexicanos y Centroamericanos. https:// books.openedition.org/cemca/327?lang=es

Vázquez, G. (2016). Los poderes y los hombres, el Golfo de Honduras en tiempos de disputa [tesis de doctorado, Centro de Investigaciones y Estudios Superiores en Antropología Social]. https://ciesas.repositorioinstitucional. mx/jspui/bitstream/1015/336/1/TE\%20V.B.\%202016\%20Gabriela\%20V\%C3\%Alzquez\%20Barke. pdf?fbclid=IwARILXCAe2nDEOe0K_cIwhQqTu-Wxp36ymoGvoSYqhWBvhQmlFoEycUllHBU 